\title{
Fatores Intervenientes da Cultura de Segurança do Paciente na Atenção Primária à Saúde
}

\author{
Sandra Dal Pai, ${ }^{1}$ Tassiane Langerdorf, ${ }^{2}$ Daiane Fernanda Brigo Alves, ${ }^{3}$ \\ Karina Andressa Cavalheiro Zimmermann, ${ }^{4}$ Pâmella Pluta, ${ }^{4}$ Evelise Moraes Berlezi, ${ }^{4}$ \\ Adriane Cristina Bernat Kolankiewicz ${ }^{5}$
}

\begin{abstract}
RESUMO
O objetivo deste estudo é identificar os fatores que interferem na cultura de segurança do paciente na atenção primária à saúde . Revisão integrativa, realizada nas bases de dados Lilacs, PubMed, WoS e Scopus, no mês de maio de 2020. Utilizou-se a classificação do nível de evidência para realizar a avaliação crítica dos estudos primários, totalizando 26 produções científicas. Os fatores que interferem na cultura de segurança do paciente na atenção primária à saúde são condições relacionadas à educação permanente, comunicação, condições de trabalho e liderança. As evidências científicas revelam que alguns fatores interferem positivamente, outros negativamente para a cultura de segurança do paciente na atenção primária à saúde e devem ser utilizados com intuito de efetivar ações de saúde para os usuários.
\end{abstract}

Palavras-chave: Segurança do paciente. Atenção primária à saúde. Gestão de riscos. Cultura organizacional.

\section{INTERVENING FACTORS OF PATIENT SAFETY CULTURE IN PRIMARY HEALTH CARE}

\section{ABSTRACT}

The objective of this stydy is to identify the factors that interfere in the culture of patient safety in primary health care. Integrative review was performed in the Lilacs, PubMed, WoS and Scopus databases in may 2019. The level of evidence classification was used to perform a critical evaluation of the primary studies. There were 26 scientific productions. The factors that interfere in the culture of patient safety in primary health care are conditions related to permanent education, communication, working conditions and leadership. The scientific evidence shows that some factors interfere positively, others negatively affect the culture of patient safety in primary health care and should be used in order to effect health actions for users. Keywords: Patient safety. Primary health care. Risk management. Organizational culture.

\footnotetext{
Hospital Vida e Saúde de Santa Rosa. Santa Rosa/RS, Brasil.

2 Universidade Federal de Santa Maria - UFSM. Santa Maria/RS, Brasil.

Hospital de São Luiz Gonzaga. São Luiz Gonzaga/RS, Brasil.

Universidade Regional do Noroeste do Estado do Rio Grande do Sul (Unijuí). Ijuí/RS, Brasil.

Autora correspondente. Universidade Regional do Noroeste do Estado do Rio Grande do Sul (Unijuí). Rua do Comércio, 3000 - Bairro Universitário - Ijuí/RS, Brasil.http://lattes.cnpq.br/7833969359741646.adriane.bernat@unijui.edu.br
} 


\section{INTRODUÇÃO}

$\mathrm{Na}$ contemporaneidade a Segurança do Paciente (SP) conceitua-se como estar livre de prejuízos acidentais ou evitáveis resultantes do cuidado. Assim, práticas ou intervenções que melhoram a SP são aquelas que reduzem a ocorrência de Eventos Adversos (EAs) evitáveis (NATIONAL... , 2015). A SP tornou-se um assunto discutido entre trabalhadores e gestores dos serviços de saúde, tendo em vista o número de eventos adversos que pode ocorrer aos usuários durante a assistência à saúde (GEHRING et al., 2013).

Para mitigar os EAs, estabelecer assistência segura e prestar cuidados isentos de erros é necessário debater sobre a cultura de segurança estabelecida no ambiente de trabalho. Entende-se que a SP é um conteúdo complexo, pois abarca uma remodelação institucional e não s define apenas como um problema centrado em um indivíduo ou vinculado somente a uma classe profissional (TIMM; RODRIGUES, 2016).

Considera-se que a cultura de segurança é o conjunto dos valores individuais e grupais, das atitudes, percepções, competências e padrões de comportamento diante de condições de saúde, que determinem a competência e habilidade no gerenciamento da segurança. Organizações permeadas por uma cultura de segurança positiva envolvem comunicações baseadas na confiança mútua, percepções compartiIhadas sobre a importância da segurança e pela confiança na eficácia das medidas preventivas (SORRA et al., 2016).

Considera-se, assim, que todos os pontos da rede de atenção à saúde devam ter cuidados assistenciais assegurados, portanto a Atenção Primária à Saúde (APS) que se define por ser o centro coordenador deste arranjo organizacional deve ter uma cultura de segurança sólida, uma vez que este local é o contato preferencial do usuário e que assiste à maioria de suas demandas (BRASIL, 2017).

Grande parte dos estudos referentes à SP está direcionada para ambientes hospitalares, no entanto a maioria dos eventos adversos que são reconhecidos no hospital pode ter se iniciado na APS (MAKEHAN et al., 2008; PAESE; DAL SASSO, 2013), pois este serviço é permeado por uma alta proporção de condições que envolvem risco de erros aos pacientes (MARCHON; JUNIOR; PAVÃO, 2015).

Neste contexto da APS, há diversos fatores da Cultura de Segurança do Paciente (CSP) que interferem tanto de forma positiva quanto negativa no cuida- do dispensado aos usuários. Estes devem ser identificados pelos trabalhadores, no intuito de conseguirem agregar às suas práticas de trabalho aqueles que mostram ser potencialidades para um bom cuidado e lapidar os fatores que são identificados como pouco contributivos ou problemáticos, para que se tenha um ambiente de saúde seguro.

Neste contexto, observa-se a partir de publicações científicas que alguns países identificam a necessidade de realizar pesquisas sobre SP na APS (HICKNER et al., 2015; CASALENGUA et al., 2013). No Brasil, esta realidade ainda é uma lacuna, que aponta para a necessidade de investigação sobre o tema, para auxiliar os profissionais a reconhecer e firmar suas responsabilidades quanto à SP, bem como unir esforços para solidificar a cultura de segurança na APS. Nesse sentido, acredita-se que a realização deste estudo irá contribuir para tal prática.

Dessa forma, este estudo tem como objetivo identificar os fatores que interferem na CSP na atenção primária à saúde.

\section{MÉTODO}

Trata-se de uma revisão integrativa. Este estudo permite a busca, avaliação crítica e a síntese de evidências disponíveis sobre o assunto investigado. Para a realização do estudo seguiram-se as seguintes etapas (MENDES; SILVEIRA; GALVÃO, 2008): 1 - elaboração da questão de pesquisa; 2 - definição dos critérios de inclusão e exclusão dos estudos primários; 3 - definição das informações a serem extraídas; 4 - avaliação das evidências e análise (FINEOUT-OVERHOLT; STILLWELL, 2011); 5 - interpretação dos resultados; 6 - apresentação da síntese do conhecimento.

Etapa 1 - estabeleceu-se a questão de pesquisa: Quais são os fatores que interferem na Cultura de Segurança do Paciente na Atenção Primária à Saúde? Para compor a amostra realizou-se uma busca, no mês maio de 2020, nas seguintes bases de dados: Literatura Latino-Americana e do Caribe em Ciências da Saúde (Lilacs), National Library of Medicine National Institutes of Health (PubMed), Web of Science (WoS) e Sci-Verse Scopus (Scopus).

Os descritores e palavras-chave utilizados para a busca foram aplicados de acordo com particularidades de cada base e obtidos por consulta nos Descritores de Ciências em Saúde (DECS) e Medical Subject Headings (Mesh). O Quadro 1 apresenta os termos e as estratégias de busca utilizados em cada base de dados. 
Quadro 1 - Estratégias de busca utilizadas nas bases de dados Lilacs, PubMed, WoS e Scopus

Estratégias de busca

Literatura Latino-Americana e do Caribe em Ciências da Saúde (Lilacs)

Atenção Primária de Saúde or serviços de saúde or estratégia saúde da família [Descritor de assunto] and segurança do paciente [Descritor de assunto]

National Library of Medicine National Institutes of Health (PubMed)

((("primary health care") or "primary care")) and "patient safety culture"

\section{Web of Science (WoS)}

TOPIC: ("primary health care") or TOPIC: ("primary care") and TOPIC: ("patient safety culture")

\section{Sci-Verse Scopus (Scopus)}

(TITLE-ABS-KEY ( "primary health care" or "primary care")) and (TITLE-ABS-KEY ("patient safety culture"))
Etapa 2 - foram definidos os seguintes critérios de inclusão: estudos primários, disponíveis na íntegra on-line, nos idiomas português, inglês ou espanhol e que respondessem à questão de pesquisa.

Quanto ao período de tempo considerado para seleção das produções, optou-se por não estabelecer um recorte temporal. A seleção das produções foi desenvolvida de forma dupla independente a fim de evitar possível viés nessa etapa. Foram localizadas 197 produções, das quais 26 compuseram o corpus do presente estudo (Figura 1). Salienta-se que as produções que se apresentaram repetidas nas bases de dados foram consideradas apenas uma vez.

Fonte: Elaborado pelas autoras.

Figura 1 - Fluxograma do corpus da seleção das publicações. Ijuí, RS/Brasil 2020

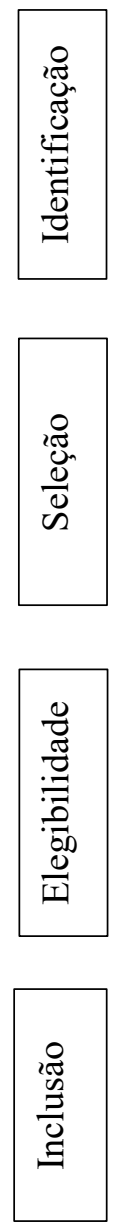

Estudos identificados através de pesquisas nas bases de dados $(n=197)$
Estudos adicionais identificados através de outras fontes $(n=0)$

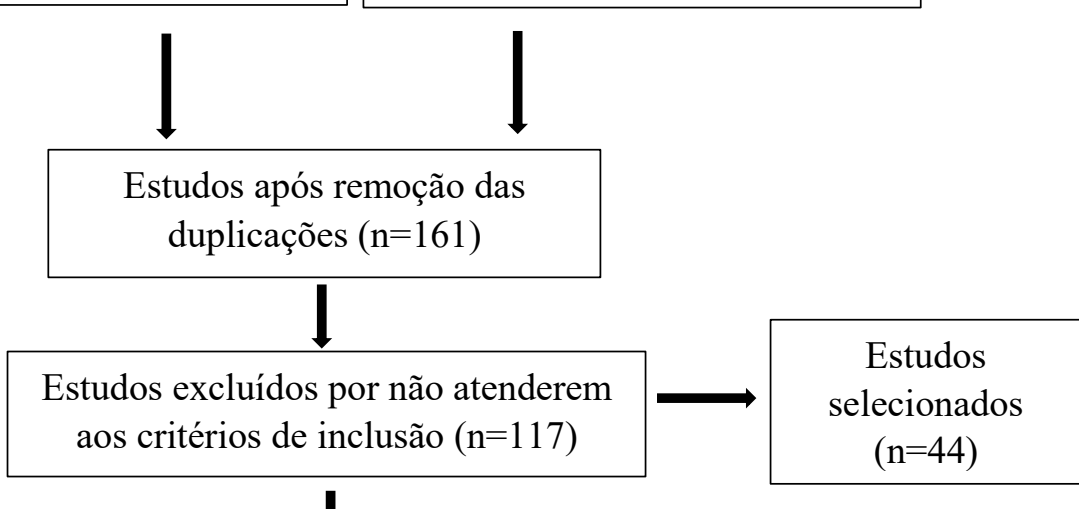

Textos completos acessados para avaliar elegibilidade $(n=44)$

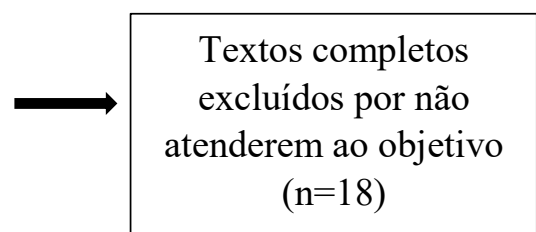

Estudos incluídos na síntese qualitativa $(\mathrm{n}=26)$ 
Etapa 3 - após seleção dos estudos primários incluídos, definiram-se as informações a serem extraídas: referência do artigo, procedência, ano de publicação, objetivo e delineamento do estudo e principais resultados. Foram respeitados os aspectos éticos na avaliação das produções utilizadas como resultados do estudo, com citação fidedigna das ideias, conceitos e definições empregadas nos artigos.

Etapa 4 - para avaliação das evidências e análise foi utilizado o método de classificação da força de evidências, que propõe a categorização de forma hierárquica, de acordo com o tipo que questão do estudo primário, a saber: Intervenção ou diagnóstico; Prognóstico ou etiologia; Significado. Considerando o corpus da pesquisa em tela, utilizou-se a classificação da força de evidências com questão clínica direcionada para intervenção ou diagnóstico, com a seguinte hierarquia: I - revisões sistemáticas ou metanálise de ensaios clínicos randomizados controlados; II - ensaios clínicos randomizados controlados; III - ensaios clínicos sem randomização; IV - estudos de coorte e caso-controle; $\mathrm{V}$ - revisões sistemáticas de estudos descritivos e qualitativos; VI - estudos descritivos ou qualitativos; VII - opinião de especialistas (FINEOUT-OVERHOLT; STILLWELL, 2011).

Etapas 5 e 6 - consistem na interpretados dos dados extraídos dos estudos primários e síntese do conhecimento para apresentação das evidências.

\section{RESULTADOS}

A seguir será apresentada a caracterização dos estudos primários analisados a partir do país em que o estudo foi desenvolvido, ano de publicação, abordagem metodológica de pesquisa e área de conhecimento dos autores (Tabela 1).

Pode-se perceber, entre as publicações, que os estudos são realizados em diferentes países, no entanto ainda de maneira discreta, indicando que pesquisas que contemplam a segurança do paciente na APS como objeto de estudo ainda são pouco desenvolvidas. As publicações concentram-se nos últimos sete anos, indicando que há um interesse crescente pela temática em foco, principalmente no Brasil, que teve um aumento de pesquisas.

O desenvolvimento de estudos com predominância da abordagem quantitativa evidencia que este método propicia maior adesão dos profissionais a participarem da pesquisa e a um diagnóstico fidedigno da realidade inquirida. Este achado também indica a relevância de contemplar pesquisas com abordagem qualitativa, a fim de contemplar aspectos relacionados aos significados atribuídos à Segurança do Paciente.

Tabela 1 - Caracterização dos estudos analisados sobre fatores intervenientes da cultura de segurança do paciente na atenção primária à saúde. Lilacs, PubMed, WoS e Scopus, 2009-2019.

\begin{tabular}{|c|c|c|}
\hline & $\mathrm{N}$ & $\%$ \\
\hline \multicolumn{3}{|c|}{ País em que o estudo foi desenvolvido } \\
\hline Espanha & 3 & 11,53 \\
\hline Holanda & 2 & 7,7 \\
\hline Brasil & 6 & 23 \\
\hline Estados Unidos da América & 2 & 7,7 \\
\hline lêmen & 1 & 3,8 \\
\hline Países Baixos & 1 & 3,8 \\
\hline Noruega & 2 & 7,7 \\
\hline Irã & 1 & 3,8 \\
\hline Turquia & 1 & 3,8 \\
\hline Colômbia & 1 & 3,8 \\
\hline Alemanha & 1 & 3,8 \\
\hline Kuwait & 1 & 3,8 \\
\hline Omã & 1 & 3,8 \\
\hline Egito & 1 & 3,8 \\
\hline Suécia & 1 & 3,8 \\
\hline Irlanda & 1 & 3,8 \\
\hline \multicolumn{3}{|l|}{ Ano de publicação } \\
\hline 2009-2012 & 3 & 11,53 \\
\hline 2013-2019 & 23 & 88,47 \\
\hline \multicolumn{3}{|c|}{ Abordagem metodológica de pesquisa } \\
\hline Quantitativo & 22 & 84,60 \\
\hline Quanti-qualitativo & 2 & 7,7 \\
\hline Controlado randomizado & 2 & 7,7 \\
\hline \multicolumn{3}{|c|}{ Área de conhecimento dos autores } \\
\hline Medicina & 13 & 50 \\
\hline Enfermagem & 6 & 23 \\
\hline Interdisciplinar & 7 & 27 \\
\hline
\end{tabular}

Fonte: Dados da pesquisa, ljuí/RS, 2020.

Houve ainda a predominância de estudos desenvolvidos pela Medicina. Isso revela a importância de expandir um olhar para outras áreas de conhecimento na saúde. Na realidade brasileira a enfermagem é a área que mais assume estudos relacionados à SP.

As informações e dados extraídos dos estudos primários analisados são apresentados no Quadro 2. 
Quadro 2 - Quadro sinóptico das produções incluídas sobre fatores intervenientes da cultura de segurança do paciente na atenção primária à saúde. Lilacs, PubMed, WoS e Scopus, 2009-2019

\begin{tabular}{|c|c|c|c|c|}
\hline Autores & Objetivo & $\begin{array}{l}\text { Instrumento } \\
\text { utilizado para } \\
\text { coleta de dados }\end{array}$ & Fatores intervenientes & N.E \\
\hline $\begin{array}{l}\text { ROMERO; } \\
\text { GONZÁLEZ; } \\
\text { CALVO (2017) }\end{array}$ & $\begin{array}{l}\text { Determinar os pontos de vista } \\
\text { dos residentes da família sobre as } \\
\text { diferentes dimensões da segurança } \\
\text { do paciente, para identificar áreas } \\
\text { potenciais para melhoria. }\end{array}$ & $\begin{array}{l}\text { MOSPSC (Medical } \\
\text { Office Survey on } \\
\text { Patient Safety } \\
\text { Culture) }\end{array}$ & $\begin{array}{l}\text { - Aprendizagem organizacional e } \\
\text { trabalho em equipe foram consideradas } \\
\text { áreas fortes. } \\
\text { - Problemas de segurança e qualidade } \\
\text { do paciente, troca de informações com } \\
\text { outras instituições e pressão e ritmo de } \\
\text { trabalho foram consideradas áreas com } \\
\text { potencial significativo de melhoria. }\end{array}$ & N6 \\
\hline $\begin{array}{l}\text { VERBAKEL et al. } \\
\text { (2015a) }\end{array}$ & $\begin{array}{l}\text { Examinar se a administração de um } \\
\text { questionário de cultura com ou sem } \\
\text { uma oficina complementar poderia } \\
\text { ser usada como uma intervenção } \\
\text { para melhorar a cultura de segurança. }\end{array}$ & \begin{tabular}{|l|} 
Scope \\
(Safety Culture \\
Questionnaire for \\
General Practice)
\end{tabular} & $\begin{array}{l}\text { - A combinação de um questionário } \\
\text { e workshop aumentou a interação } \\
\text { dos membros da equipe e nutriu } \\
\text { sentimentos. } \\
\text { - Os workshops ajudaram a instituir um } \\
\text { procedimento de relatório de incidentes } \\
\text { (eventos adversos) e foram abordados } \\
\text { temas sobre a educação em segurança } \\
\text { do paciente. }\end{array}$ & N2 \\
\hline $\begin{array}{l}\text { WEBAIR et al. } \\
(2015)\end{array}$ & $\begin{array}{l}\text { Fornecer uma avaliação básica da } \\
\text { cultura de segurança do paciente em } \\
\text { ambientes de atenção primária em } \\
\text { Al-Mukala/ lêmen. }\end{array}$ & $\begin{array}{l}\text { MOSPSC (Medical } \\
\text { Office Survey on } \\
\text { Patient Safety } \\
\text { Culture) }\end{array}$ & $\begin{array}{l}\text { - A cultura de SP foi positiva, com } \\
\text { exceção das dimensões Abertura da } \\
\text { comunicação, Pressão e ritmo do } \\
\text { trabalho e Seguimento da assistência do } \\
\text { paciente. } \\
\text { - O maior percentual de respostas } \\
\text { positivas foi para Trabalho em equipe e } \\
\text { Aprendizagem organizacional. }\end{array}$ & N6 \\
\hline $\begin{array}{l}\text { VERBAKEL et al. } \\
\text { (2015b) }\end{array}$ & $\begin{array}{l}\text { Estudar o efeito da administração } \\
\text { de um questionário de CSP } \\
\text { (intervenção I), o questionário junto } \\
\text { com uma oficina baseada na prática } \\
\text { (intervenção II) e sem intervenção } \\
\text { (controle) em } 30 \text { práticas gerais nos } \\
\text { Países Baixos. }\end{array}$ & $\begin{array}{l}\text { MaPSaF } \\
\text { (Manchester } \\
\text { Patient Safety } \\
\text { Framework) }\end{array}$ & $\begin{array}{l}\text { - A administração de um questionário } \\
\text { de cultura de segurança unicamente ou } \\
\text { integrado em uma oficina aumentou os } \\
\text { relatórios de incidente, no entanto o } \\
\text { efeito foi muito maior nas práticas que } \\
\text { receberam a oficina. } \\
\text { - As oficinas são formas de intervenção } \\
\text { educativa. }\end{array}$ & N2 \\
\hline Peña et al. (2015) & $\begin{array}{l}\text { Conhecer a cultura de segurança do } \\
\text { paciente em organizações de saúde } \\
\text { e realizar uma pesquisa para cultura } \\
\text { de segurança entre os profissionais } \\
\text { de atenção primária dos centros } \\
\text { de saúde da Espanha e analisar as } \\
\text { dimensões que influenciam a CSP. }\end{array}$ & \begin{tabular}{|l|} 
MOSPSC \\
(Medical Office \\
Survey on Patient \\
Safety Culture)
\end{tabular} & $\begin{array}{l}\text { - O trabalho em equipe foi uma das } \\
\text { dimensões mais bem pontuadas. } \\
\text { - Aprendizagem organizacional teve } \\
\text { pontuação postiva. } \\
\text { - Setenta por cento dos participantes } \\
\text { têm trabalhado no mesmo HC por mais } \\
\text { de } 6 \text { anos e } 84,2 \% \text { trabalham de } 33 \text { a } 40 \\
\text { horas/semana. } \\
\text { - Pressão e ritmo de trabalho é a } \\
\text { dimensão de pontuação mais baixa. } \\
\text { - Os profissionais com responsabilidades } \\
\text { gerenciais mostraram maior valor de } \\
\text { ISSP. }\end{array}$ & $\begin{array}{l}\text { Estudo } \\
\text { Metodológico }\end{array}$ \\
\hline $\begin{array}{l}\text { BONDEVIK, et al., } \\
2014\end{array}$ & $\begin{array}{l}\text { Investigar as atitudes de SP entre os } \\
\text { prestadores de cuidados de saúde na } \\
\text { atenção primária norueguesa. }\end{array}$ & $\begin{array}{l}\text { SAQ } \\
\text { (Safety Attitudes } \\
\text { Questionnaire) }\end{array}$ & $\begin{array}{l}\text { - Nas clínicas de } \mathrm{OOH} \text {, as enfermeiras } \\
\text { obtiveram resultados significativamente } \\
\text { superiores aos médicos em clima de } \\
\text { segurança e satisfação no trabalho. }\end{array}$ & N6 \\
\hline $\begin{array}{l}\text { VERBAKEL (et al., } \\
\text { 2014) }\end{array}$ & $\begin{array}{l}\text { Explorar percepções de CSP em nove } \\
\text { diferentes tipos de profissões de } \\
\text { atenção primária e estudar possíveis } \\
\text { diferenças }\end{array}$ & \begin{tabular}{|l|} 
Scope-PC \\
(Safety Culture \\
Questionnaire for \\
General practice- \\
Primary Care)
\end{tabular} & $\begin{array}{l}\text { - A intenção de reportar eventos } \\
\text { apresentou dois grandes desvios } \\
\text { negativos para terapia ocupacional e } \\
\text { dietética. }\end{array}$ & N6 \\
\hline
\end{tabular}




\begin{tabular}{|c|c|c|c|c|}
\hline $\begin{array}{l}\text { TABRIZCHI; } \\
\text { SEDAGHAT (2012) }\end{array}$ & $\begin{array}{l}\text { Determinar os escores de cultura de } \\
\text { segurança do paciente em centros } \\
\text { de saúde e comparar os resultados } \\
\text { com os dados existentes dos hospitais } \\
\text { iranianos e o banco de dados } 2009 \\
\text { AHRQ }\end{array}$ & \begin{tabular}{|l|} 
HSOPSC (Hospital \\
Survey on Patient \\
Safety Culture)
\end{tabular} & $\begin{array}{l}\text { - O maior percentual de respostas } \\
\text { positivas foi em Trabalho em } \\
\text { equipe, Suporte gerencial para SP e } \\
\text { Aprendizagem organizacional. } \\
\text { - Não houve relação entre os anos de } \\
\text { trabalho em seu centro atual. } \\
\text { - As dimensões que mostram a maior } \\
\text { diferença foram: Pessoal, Resposta } \\
\text { não punitiva ao erro, Feedback e } \\
\text { comunicação sobre erro. }\end{array}$ & $\begin{array}{l}\text { Estudo } \\
\text { metodológico. }\end{array}$ \\
\hline $\begin{array}{l}\text { BODUR; FILIZ } \\
\text { (2009) }\end{array}$ & $\begin{array}{l}\text { Avaliar a cultura de segurança do } \\
\text { paciente em unidades de atenção } \\
\text { primária. }\end{array}$ & $\begin{array}{l}\text { HSOPSC (Hospital } \\
\text { Survey on Patient } \\
\text { Safety Culture) }\end{array}$ & $\begin{array}{l}\text { - A porcentagem de respostas positivas } \\
\text { foi maior para Trabalho em equipe } \\
\text { dentro das unidades, Percepção geral } \\
\text { de segurança e Trabalho em equipe em } \\
\text { unidades hospitalares e menor para } \\
\text { Frequência de relatórios de eventos e } \\
\text { Resposta não punitiva ao erro. } \\
\text { - O pessoal que trabalhava há mais de } 10 \\
\text { anos na unidade atual teve escore de CSP } \\
\text { significativamente maior. }\end{array}$ & N6 \\
\hline $\begin{array}{l}\text { ASTUDILLO, et al. } \\
(2015)\end{array}$ & $\begin{array}{l}\text { Identificar a percepção que dos } \\
\text { trabalhadores de una Empresa } \\
\text { de Saúde acerca da aplicação, } \\
\text { na instituição, dos diferentes } \\
\text { componentes da Cultura de } \\
\text { Segurança do Paciente durante o ano } \\
\text { de } 2015\end{array}$ & $\begin{array}{l}\text { HSOPSC (Hospital } \\
\text { Survey on Patient } \\
\text { Safety Culture) }\end{array}$ & $\begin{array}{l}\text { - A porcentagem mais alta foi para: } \\
\text { A equipe se trata com respeito, O } \\
\text { chefe aceita as sugestões do pessoal } \\
\text { para melhorar a SP, Se discute formas } \\
\text { de prevenir falhas da assistência à } \\
\text { saúde para que não voltem a ocorrer } \\
\text { novamente, Se fala livremente quando } \\
\text { se observa algo que poderia afetar } \\
\text { negativamente o cuidado do paciente, } \\
\text { Se está fazendo coisas ativamente para } \\
\text { melhorar a segurança do paciente. } \\
\text { - Itens com porcentagem mais baixa: } \\
\text { Pessoal e Resposta não punitiva ao erro. }\end{array}$ & N6 \\
\hline $\begin{array}{l}\text { MARCHON; } \\
\text { JUNIOR; PAVÃO } \\
(2015)\end{array}$ & $\begin{array}{l}\text { Avaliar a ocorrência de incidentes } \\
\text { no cuidado à saúde ao paciente na } \\
\text { atenção primária brasileira. }\end{array}$ & $\begin{array}{l}\text { PCISME } \\
\text { (Primary Care } \\
\text { International } \\
\text { Study of Medical } \\
\text { Errors) }\end{array}$ & \begin{tabular}{|l|} 
- Falta de experiência e má formação \\
profissional (falhas no cuidado), \\
Desqualificação profissional (falhas \\
no cuidado), Paciente não segue as \\
orientações da equipe. \\
- Falha no acompanhamento da equipe \\
ESF (falha na comunicação com paciente) \\
\end{tabular} & N6 \\
\hline $\begin{array}{l}\text { HICKNER et al. } \\
(2015)\end{array}$ & $\begin{array}{l}\text { Examinar as diferenças na segurança } \\
\text { do paciente, percepções culturais } \\
\text { entre os prestadores, gestão e } \\
\text { pessoal em uma grande pesquisa } \\
\text { nacional sobre cultura de segurança } \\
\text { nas práticas ambulatoriais no EUA. }\end{array}$ & $\begin{array}{l}\text { MOSPSC (Medical } \\
\text { Office Survey on } \\
\text { Patient Safety } \\
\text { Culture) }\end{array}$ & $\begin{array}{l}\text { - O trabalho em equipe foi o composto } \\
\text { de CSP com os escore mais altos em } \\
\text { todas as posições do trabalho, enquanto } \\
\text { que a pressão do trabalho e o ritmo } \\
\text { foram compostos com os menores } \\
\text { índices em todos os cargos. } \\
\text { - Gerenciamento sempre teve } \\
\text { percepções mais positivas da CSP em } \\
\text { quase todas as medidas, comparado a } \\
\text { outros cargos. }\end{array}$ & N6 \\
\hline $\begin{array}{l}\text { HOFFMANN et al. } \\
\text { (2014) }\end{array}$ & $\begin{array}{l}\text { Avaliar os efeitos de FraTrix sobre a } \\
\text { cultura de segurança na prática geral. }\end{array}$ & $\begin{array}{l}\text { (FraTrix) } \\
\text { Frankfurt Patient } \\
\text { Safety Matrix. } \\
\end{array}$ & $\begin{array}{l}\text { - A implementação da ação visou, entre } \\
\text { vários pontos, à educação e treinamento. }\end{array}$ & N2 \\
\hline $\begin{array}{l}\text { GORMAN; } \\
\text { O'MALLEY; } \\
\text { FAGNAN (2012) }\end{array}$ & $\begin{array}{l}\text { Investigar a relação entre a segurança } \\
\text { geral percebida e a qualidade } \\
\text { dos cuidados e características do } \\
\text { trabalho: tamanho da prática e grau } \\
\text { de instituição do HIT. }\end{array}$ & \begin{tabular}{|l|} 
(MOSPSC) \\
Medical Office \\
Survey on Patient \\
Safety Culture.
\end{tabular} & $\begin{array}{l}\text { - Os clínicos e a gerência tiveram maior } \\
\text { porcentagem na pontuação de qualidade } \\
\text { geral positiva, comparados aos demais } \\
\text { membros da equipe. }\end{array}$ & N6 \\
\hline
\end{tabular}




\begin{tabular}{|c|c|c|c|c|}
\hline $\begin{array}{l}\text { GHOBASHI et al. } \\
\text { (2014) }\end{array}$ & $\begin{array}{l}\text { Avaliar a conscientização dos } \\
\text { membros da equipe de atenção } \\
\text { primária sobre cultura de segurança } \\
\text { do paciente e explorar as áreas } \\
\text { de deficiência e oportunidades de } \\
\text { melhoria em relação a esta questão. }\end{array}$ & \begin{tabular}{|l|} 
HSOPSC (Hospital \\
Survey on Patient \\
Safety Culture)
\end{tabular} & $\begin{array}{l}\text { - Trabalho em equipe dentro das } \\
\text { unidades centrais e a melhoria contínua } \\
\text { da aprendizagem organizacional foram as } \\
\text { dimensões mais altas. } \\
\text { - A frequência de relatórios de eventos } \\
\text { entre todos os funcionários é a segunda } \\
\text { maior dimensão de SP entre todas as } \\
\text { dimensões investigadas, pois tem maior } \\
\text { positividade geral. }\end{array}$ & N6 \\
\hline $\begin{array}{l}\text { PAESE; DAL SASSO } \\
(2013)\end{array}$ & $\begin{array}{l}\text { Analisar as atitudes que evidenciam } \\
\text { a CSP pelos profissionais das } \\
\text { equipes da Estratégia de Saúde da } \\
\text { Família e do Programa de Agentes } \\
\text { Comunitários de Saúde }\end{array}$ & $\begin{array}{l}\text { (SAQ) Safety } \\
\text { Attitudes } \\
\text { Questionnaire. }\end{array}$ & $\begin{array}{l}\text { - Atitude Erro foi a média mais } \\
\text { baixa entre a categoria de ACS, Téc. } \\
\text { enfermagem e enfermeiros. } \\
\text { - ACS evidencia o trabalho em equipe } \\
\text { diferente da equipe de enfermagem. } \\
\text { - Enfermeiros e ACS possuem } \\
\text { percepções distintas sobre Gerência do } \\
\text { Centro de Saúde. }\end{array}$ & N6 \\
\hline REE; SIRI (2019) & $\begin{array}{l}\text { 1. explorar as pontuações nas } \\
\text { dimensões da CSP em asilos e } \\
\text { serviços de assistência domiciliar; } \\
\text { 2. diferenças entre asilos e serviços } \\
\text { de assistência domiciliar nas } \\
\text { dimensões da CSP; } \\
\text { 3. o grau em que as diferentes } \\
\text { dimensões de uma CSP preveem as } \\
\text { percepções gerais dos funcionários } \\
\text { sobre a SP em asilos e serviços de } \\
\text { atendimento domiciliar. }\end{array}$ & \begin{tabular}{|l|} 
Norwegian \\
version of the \\
Nursing Home \\
Survey on Patient \\
Safety Culture. \\
\end{tabular} & $\begin{array}{l}\text {-Os serviços de assistência domiciliar } \\
\text { pontuaram significativamente mais no } \\
\text { trabalho em equipe; } \\
\text { - A porcentagem média de pontuações } \\
\text { positivas foi a mesma nos lares de } \\
\text { idosos e nos cuidados domiciliares } \\
\text { em relação a "suporte gerencial e } \\
\text { aprendizado organizacional" e feedback e } \\
\text { comunicação sobre incidentes. } \\
\text { - Ambos os locais tiveram pontuações } \\
\text { mais baixas na frequência de notificação } \\
\text { de incidentes. }\end{array}$ & N6 \\
\hline $\begin{array}{l}\text { LAWATI et al. } \\
\text { (2019) }\end{array}$ & $\begin{array}{l}\text { Explorar o entendimento dos } \\
\text { profissionais da linha de frente } \\
\text { da APS em relação à cultura de } \\
\text { segurança do paciente nas unidades } \\
\text { de saúde de Omã. }\end{array}$ & $\begin{array}{l}\text { HSOPSC (Hospital } \\
\text { Survey on Patient } \\
\text { Safety Culture) }\end{array}$ & $\begin{array}{l}\text { - No geral, a equipe tinha um forte senso } \\
\text { de trabalho em equipe, evidenciaram } \\
\text { bom aprendizado organizacional. } \\
\text { - As dimensões que receberam } \\
\text { menores escores estavam relacionados } \\
\text { a problemas de comunicação entre os } \\
\text { funcionários, resposta não punitiva } \\
\text { a erros, frequência de notificação } \\
\text { de eventos e erros ao transferir e } \\
\text { acompanhar pacientes para outros níveis } \\
\text { de assistência. } \\
\text { - A área com a menor pontuação positiva } \\
\text { foi para o pessoal inadequado. } \\
\text { - Cultura de culpa. }\end{array}$ & N6 \\
\hline $\begin{array}{l}\text { SHAFEI, ZAYED } \\
\text { (2919) }\end{array}$ & $\begin{array}{l}\text { Investigar as atitudes de SP entre os } \\
\text { prestadores de cuidados de saúde } \\
\text { nas instalações da APS em Gizé } \\
\text { para explorar áreas de deficiência } \\
\text { e oportunidades de melhoria e } \\
\text { identificar se as variações na CSP } \\
\text { estão correlacionadas à formação } \\
\text { profissional, gênero e idade dos } \\
\text { prestadores de cuidados. }\end{array}$ & SAQ-AV & $\begin{array}{l}\text { - Houve variações significativas nas } \\
\text { atitudes de SP relacionadas à idade e } \\
\text { formação profissional. } \\
\text { - Farmacêuticos tiveram a menor } \\
\text { pontuação média em cinco dos seis } \\
\text { domínios. } \\
\text { - Gerentes tiveram atitudes mais } \\
\text { positivas sobre questões de SP nas } \\
\text { práticas de sua responsabilidade, } \\
\text { comparados aos funcionários. } \\
\text { - Pessoas com } 50 \text { anos ou mais tiveram } \\
\text { escores com diferença estatística nos } \\
\text { domínios satisfação e condições de trabalho. } \\
\text { - Médicos evidenciam menor percentual } \\
\text { para trabalho em equipe. }\end{array}$ & N6 \\
\hline $\begin{array}{l}\text { GONZÁLEZ- } \\
\text { FORMOSO et al. } \\
(2019\end{array}$ & $\begin{array}{l}\text { Avaliar a eficácia de uma intervenção } \\
\text { educacional para melhorar a cultura } \\
\text { de segurança nas unidades de ensino } \\
\text { de Medicina Familiar e Comunitária } \\
\text { em uma região da Europa Atlântica. }\end{array}$ & $\begin{array}{l}\text { SOPS (Survey On } \\
\text { Patient Safety } \\
\text { Culture) }\end{array}$ & $\begin{array}{l}\text { - Feedback e comunicação sobre erro } \\
\text { tiveram pequeno efeito positivo no } \\
\text { número de eventos relatados. }\end{array}$ & N2 \\
\hline
\end{tabular}




\begin{tabular}{|c|c|c|c|c|}
\hline $\begin{array}{l}\text { RAIMONDI et al. } \\
\text { (2019) }\end{array}$ & $\begin{array}{l}\text { Comparar a cultura de segurança } \\
\text { do paciente entre as categorias } \\
\text { profissionais atuantes na Atenção } \\
\text { Primária à Saúde. }\end{array}$ & \begin{tabular}{|l|} 
Pesquisa sobre \\
Cultura de \\
Segurança do \\
Paciente para \\
Atenção Primária.
\end{tabular} & $\begin{array}{l}\text { - Categorias profissionais apresentaram } \\
\text { cultura positiva de segurança do } \\
\text { paciente, exceto os ACS. } \\
\text { - Médicos e ACS identificam baixas } \\
\text { médias para CSP. }\end{array}$ & N6 \\
\hline $\begin{array}{l}\text { RAIMONDI; } \\
\text { BERNAL; } \\
\text { MATSUDA (2019) }\end{array}$ & $\begin{array}{l}\text { Analisar se a cultura de segurança } \\
\text { do paciente entre os profissionais da } \\
\text { Atenção Primária à Saúde difere entre } \\
\text { as equipes de saúde. }\end{array}$ & \begin{tabular}{|l|} 
Pesquisa sobre \\
Cultura de \\
Segurança do \\
Paciente para \\
Atenção Primária.
\end{tabular} & $\begin{array}{l}\text { - Comunicação e acompanhamento } \\
\text { e troca de informações com outras } \\
\text { instituições apresentam-se positivas, } \\
\text { mas são consideradas pontos fracos da } \\
\text { Cultura de Segurança do Paciente. } \\
\text { - Necessidade de apoio dos gestores. } \\
\end{array}$ & N6 \\
\hline $\begin{array}{l}\text { SOUZA et al. } \\
\text { (2019) }\end{array}$ & $\begin{array}{l}\text { Avaliar a cultura de segurança do } \\
\text { paciente na Atenção Primária à } \\
\text { Saúde. }\end{array}$ & $\begin{array}{l}\text { Safety Attitudes } \\
\text { Questionnaire } \\
\text { Ambulatory } \\
\text { Version. }\end{array}$ & $\begin{array}{l}\text { - Atuar há mais tempo no serviço de } \\
\text { saúde favorece a CSP. } \\
\text { - Enfermeiros pontuam negativamente } \\
\text { para "Satisfação no trabalho". } \\
\text { - A comunicação teve avaliação negativa. } \\
\text { - Educação Permanente apresentou } \\
\text { cultura negativa. } \\
\text { - Profissionais sentem-se valorizados } \\
\text { pelos gestores. } \\
\text { - Educação permanente melhora a SP. }\end{array}$ & N6 \\
\hline $\begin{array}{l}\text { MACEDO et al. } \\
(2019)\end{array}$ & $\begin{array}{l}\text { Avaliar a Cultura de Segurança do } \\
\text { Paciente sob a perspectiva dos } \\
\text { enfermeiros na Atenção Primária à } \\
\text { Saúde. }\end{array}$ & \begin{tabular}{|l|} 
(MOSPSC) \\
Medical Office \\
Survey on Patient \\
Safety Culture
\end{tabular} & $\begin{array}{l}\text { - Houve problemas relacionados com } \\
\text { a troca de informação com outras } \\
\text { instituições, ao processo de trabalho, } \\
\text { medo da culpa, punição pelos erros e } \\
\text { insatisfação referentes à gestão. }\end{array}$ & N6 \\
\hline $\begin{array}{l}\text { ERICSSON et al. } \\
(2019)\end{array}$ & $\begin{array}{l}\text { Investigar as percepções dos } \\
\text { pacientes sobre suas reuniões com } \\
\text { profissionais de saúde e até que } \\
\text { ponto eles acreditam que podem } \\
\text { influenciar na segurança do paciente } \\
\text { nessas reuniões. }\end{array}$ & - & $\begin{array}{l}\text { - A maioria dos entrevistados relatou ser } \\
\text { fácil perguntar a médicos e enfermeiros e } \\
\text { apontar se algo parecia estranho em sua } \\
\text { assistência. } \\
\text { - Um dos grupos concordou em maior } \\
\text { grau que os pacientes podem contribuir } \\
\text { para um cuidado mais seguro. } \\
\text { - Quase um terço dos entrevistados } \\
\text { relatou ter sofrido danos nos cuidados de } \\
\text { saúde nos últimos } 10 \text { anos. }\end{array}$ & N6 \\
\hline $\begin{array}{l}\text { MADDEN et al. } \\
(2019)\end{array}$ & $\begin{array}{l}\text { Avaliar a viabilidade de uma } \\
\text { intervenção destinada a melhorar } \\
\text { a segurança do paciente na prática } \\
\text { geral. }\end{array}$ & $\begin{array}{l}\text { GP-SafeQuest } \\
\text { questionário }\end{array}$ & $\begin{array}{l}\text { - A maioria respondeu positivamente } \\
\text { sobre a intervenção. }\end{array}$ & N2 \\
\hline
\end{tabular}

Fonte: Dados da pesquisa, Ijuí/RS, 2020.

A avaliação crítica dos trabalhos mostrou que houve predominância de estudos com força de evidência VI, 73\% (n=19). Da interpretação e síntese do conhecimento emergiu a categorização de quatro fa- tores intervenientes da cultura de segurança do pacientes na APS, sendo eles: educação permanente, comunicação, condições de trabalho e liderança (Quadro 3). 
Quadro 3 - Fatores intervenientes da cultura de segurança do paciente na atenção primária à saúde. Lilacs, PubMed, WoS e Scopus, 2009-2019

\begin{tabular}{|c|c|}
\hline Fatores intervenientes & Fatores relacionados \\
\hline Educação permanente & $\begin{array}{l}\text { - Intervenção educativa (MARCHON; JUNIOR; PAVÃO, 2015; VERBAKEL et al., 2015a, b; HOFFMANN } \\
\text { et al., 2014; SOUZA et al., 2019; MADDEN et al., 2019) } \\
\text { - Aprender com os erros (PAESE; DAL SASSO, 2013) } \\
\text { - Trocas de experiências (SOUZA et al., 2019) }\end{array}$ \\
\hline Comunicação & $\begin{array}{l}\text { - Trabalho em equipe (PAESE; DAL SASSO, 2013; MARCHON; JUNIOR; PAVÃO, 2015; HICKNER et al., } \\
\text { 2015; ROMERO; GONZÁLEZ; CALVO, 2017; VERBAKEL et al., 2015a; WEBAIR et al., 2015; PEÑA et al., } \\
\text { 2015; TABRIZCHI; SEDAGHAT, 2012; BODUR; FILIZ, 2009; ASTUDILLO et al., 2015; GHOBASHI et al., } \\
\text { 2014; REE; SIRI, 2019; LAWATI et al., 2019; SHAFEI; ZAYED, 2019) } \\
\text { - Aprendizagem organizacional (ROMERO; GONZÁLEZ; CALVO, 2017; WEBAIR et al., 2015; PEÑA et } \\
\text { al., 2015; TABRIZCHI; SEDAGHAT, 2012; ASTUDILLO et al., 2015; GHOBASHI et al., 2014; REE; SIRI, } \\
\text { 2019; LAWATI et al., 2019) } \\
\text { - Relatar eventos adversos (PAESE; DAL SASSO, 2013; VERBAKEL et al., 2015a, b, 2014; TABRIZCHI; } \\
\text { SEDAGHAT, 2012; BODUR; FILIZ, 2009; ASTUDILLO et al., 2015; GHOBASHI et al., 2014; REE; SIRI, } \\
\text { 2019; GONZÁLEZ-FORMOSO et al., 2019) } \\
\text { - A falha causa EA (MARCHON; JUNIOR; PAVÃO, 2015; SOUZA et al., 2019; MACEDO et al., 2019; } \\
\text { ERICSSON et al., 2019) } \\
\text { - Acompanhamento do paciente (RAIMONDI; BERNAL; MATSUDA, 2019) }\end{array}$ \\
\hline Condições de trabalho & $\begin{array}{l}\text { - Tempo de atuação (PEÑA et al., 2015; TABRIZCHI; SEDAGHAT, 2012; BODUR; FILIZ, 2009; SHAFEI; } \\
\text { ZAYED, 2019; SOUZA et al., 2019) } \\
\text { - Sobrecarga de trabalho (PAESE; DAL SASSO, 2013; HICKNER et al., 2015; ROMERO; GONZÁLEZ; } \\
\text { CALVO, 2017; PEÑA et al., 2015; ASTUDILLO et al., 2015; LAWATI et al., 2019; SHAFEI; ZAYED, 2019; } \\
\text { GONZÁLEZ-FORMOSO et al., 2019) } \\
\text { - Categoria profissional (PAESE; DAL SASSO, 2013; SHAFEI; ZAYED, 2019; RAIMONDI; BERNAL; } \\
\text { MATSUDA, 2019) } \\
\text { - Satisfação (BONDEVIK et al., 2014; RAIMONDI; BERNAL; MATSUDA, 2019; SOUZA et al., 2019) }\end{array}$ \\
\hline Liderança & $\begin{array}{l}\text { - Líderes evidenciam melhor a SP (HICKNER et al., 2015; PEÑA et al., 2015; TABRIZCHI; SEDAGHAT, } \\
\text { 2012; GORMAN; O'MALLEY; FAGNAN, 2012; SHAFEI; ZAYED, 2019) } \\
\text { - Proatividade (WEBAIR et al., 2015) } \\
\text { - Apoio dos gestores (ASTUDILLO et al., 2015; RAIMONDI; BERNAL; MATSUDA, 2019; SOUZA et al., } \\
\text { 2019; MACEDO et al., 2019) }\end{array}$ \\
\hline
\end{tabular}

Fonte: Dados da pesquisa, ljuí/RS, 2018.

\section{DISCUSSÃO}

Neste estudo foi evidenciado que aspectos relacionados à educação permanente contribuem para alcançar avanços na cultura de segurança da APS (SOUZA et al., 2019; MADDEN et al., 2019). Intervenções educativas realizadas por meio de workshops foram consideradas necessárias para promover mudanças na CSP na APS, pois permitem o compartilhamento de experiências, o aprender uns com os outros e o engajamento entre trabalhadores, colaboram para a consciência dos problemas, uma vez que mudam opiniões quando se discute sobre medidas a serem tomadas (VERBAKEL et al., 2015a).

Pesquisa realizada com trabalhadores da APS evidenciou no domínio Educação Permanente que atitudes educativas são meios para partilhar conhecimentos e habilidades laborais dos membros, princi- palmente quando a equipe é composta por diferentes categorias profissionais, o que favorece um olhar ampliado para a SP (SOUZA et al., 2019).

Para os trabalhadores, reunir-se e dedicar tempo para debater esta temática, por meio da análise de dados nacionais e internacionais sobre danos iatrogênicos, faz com que compreendam a necessidade de mudança de cultura (VERBAKEL et al., 2015a, b; 2014). Estas reflexões permitirão rever suas práticas assistenciais (MARCHON; JUNIOR; PAVÃO, 2015), contribuir na identificação de incidentes e na adoção de planos de ação institucionais (TABRIZCHI; SEDAGHAT, 2012). Ainda incentiva a comunicação entre os profissionais e os pacientes, no intuito de discutir os erros para que ocorra o aprendizado coletivo, evitando a cultura punitiva nos serviços da APS (PAESE; DAL SASSO, 2013). 
Ações de educação permanente para profissionais de saúde com certa periodicidade contribuem para minimizar a ocorrência dos incidentes e fortalecem a prática assistencial do trabalhador. É fundamental, da mesma forma, incluir o paciente e o familiar nas ações de educação, uma vez que estes podem atuar como barreira para evitar incidentes na APS (MARCHON; JUNIOR; PAVÃO, 2015).

No que se refere às ações educativas no âmbito acadêmico, evidencia-se a necessidade do desenvolvimento de atividades que contemplem a SP durante a formação de estudantes da área da saúde, pois aumentam e consolidam a cultura, permitindo o fortalecimento da temática na área (ASTUDILLO et al., 2015). Estudo que avaliou a CSP com residentes de Medicina do primeiro ano mostra melhores resultados para estes, e os piores resultados para os residentes do último ano, podendo indicar que o conhecimento adquirido durante a Graduação fica fragilizado à medida que os residentes adquirem habilidades e responsabilidades clínicas, sendo altamente prejudicial para a SP (ROMERO; GONZÁLEZ; CALVO, 2017).

Outro aspecto que interfere na CSP na APS é a Comunicação, pois se destaca como um fator que fortalece o trabalho em equipe, apoia a melhoria contínua (LAWATI et al., 2019) e demonstra que as pessoas gostam de trabalhar em conjunto (GHOBASHI et al., 2014; LAWATI et al., 2019). Também colabora para evitar falhas nas trocas de informações entre os pontos da rede de atenção e de comunicação com o paciente (MARCHON; JUNIOR; PAVÃO, 2015; SOUZA et al., 2019; MACEDO et al., 2019) e quando não efetiva, pode resultar em uma assistência insegura (RAIMONDI; BERNAL; MATSUDA, 2019). Estudo evidencia baixa pontuação na dimensão transferência e acompanhamento dos pacientes, quando estes estão na APS e necessitam encaminhamentos para cuidados secundários. Este achado indica a necessidade de melhorar a comunicação entre as equipes (LAWATI et al., 2019).

A comunicação é compreendida como a base do trabalho diário dos serviços de saúde e identificada como ponto forte para melhorar áreas problemáticas da SP (HICKNER et al., 2015; ROMERO; GONZÁLEZ; CALVO, 2017). Favorece a discussão e a troca de experiências, o que leva ao compartilhamento de conhecimento e à aprendizagem organizacional (PEÑA et al., 2015; TABRIZCHI; SEDAGHAT, 2012; ASTUDILLO et al., 2015; GHOBASHI et al., 2014; REE; SIRI, 2019). Ainda, a reciprocidade comunicativa alimenta os sentimentos da equipe e fortalece a confiança mútua, estimulando discussões sobre SP durante as atividades diárias e reuniões da equipe (VERBAKEL et al., 2015a).
O engajamento mútuo entre os trabalhadores fortalece o diálogo, a discussão/compartilhamento de saberes entre diferentes categorias profissionais, pois quando abordados em uma oficina sobre a temática SP, conseguem discutir os termos, criar e negociar uma compreensão coletiva, visto que inicialmente pode haver divergência entre o conhecimento das terminologias e definições comuns. Isso revela que a equipe multiprofissional atuante na APS deve ser inserida e estimulada a discutir sobre a temática, pois os profissionais podem apresentar limitações sobre este assunto, devido ao fato de não ter conhecimento prévio durante sua formação acadêmica (VERBAKEL et al., 2015a).

No cotidiano laboral há dificuldade dos profissionais em relatar a ocorrência de EA nos serviços da APS. A fim de superar esta fragilidade, é importante estabelecer um clima em que a equipe de saúde possa expor erros possíveis ou presentes, sem medo de punições (TABRIZCHI; SEDAGHAT, 2012), pois em uma equipe em que há confiança mútua entre colegas, os eventos podem ser discutidos e resolvidos no próprio grupo, sem que haja a obrigação de denunciar os erros dos colegas (REE; SIRI, 2019). Nesse sentido, momentos que permitam o diálogo aberto com a equipe, livres do sentimento de culpa e vergonha e não aliados à punição, contribuem para o reconhecimento que os problemas existem (BODUR; FILIZ, 2009; ASTUDILLO et al., 2015) e revela-se como um componente importante do aprendizado organizacional com base no fluxo de informações (GONZÁLEZ-FORMOSO et al., 2019).

Em uma cultura punitiva, há o desencorajamento em desvelar EA, devido ao medo da punição, à ausência de reconhecimento de erros, ao bloqueio da possibilidade de aprender com erro, receio de perder o emprego ou ao pensamento de que os erros são provocados por descuido (PAESE; DAL SASSO, 2013; GHOBASHI et al., 2014; LAWATI et al., 2019; MACEDO et al., 2019). A dificuldade de relatar eventos também está relacionada à sobrecarga de trabalho, pois quando o trabalhador considera esta ação pouco importante, não se comunica de maneira oportuna (ASTUDILLO et al., 2015) ou não tem um bom feedback sobre seus atos (TABRIZCHI; SEDAGHAT, 2012). Trabalhar discutindo a não culpabilização e erro com as equipes é uma alternativa para oportunizar a discussão, no intuito de desenvolver o pensar crítico sobre as ações de cuidado e atitudes diante do próprio erro e do erro do grupo, ou seja, considera-lo como ocasião de aprendizado para inibir novos eventos oriundos da mesma causa (PAESE; DAL SASSO, 2013). 
Outro fator que desfavorece a notificação de EA na APS é o fato de que o serviço ainda está em estágio inicial do desenvolvimento de notificação dos incidentes relacionados à SP (VERBAKEL et al., 2014) ou porque alguns serviços de saúde possuem sistema eletrônico precário, ou nem exista sistemas padronizados de registro ou notificação de incidentes, o que torna o acompanhamento dos pacientes mais difícil (MARCHON; JUNIOR; PAVÃO, 2015; WEBAIR et al., 2015; LAWATI et al., 2019). A Tecnologia da Informação é uma das áreas que favorece a troca de informações entre os diferentes serviços, beneficiando-os ao máximo, pois é compartilhada pelos diferentes níveis e dispositivos de assistência. É desejável, no entanto, que o profissional assistencial envolva-se mais no processo comunicativo e não deixe somente canalizado para os serviços de informática (ROMERO; GONZÁLEZ; CALVO, 2017).

A falha na comunicação entre profissionais é vista como o fator contribuinte mais comum para ocorrência de incidente na APS (REE; SIRI, 2019), pois aponta como dificuldades para o bom relacionamento da equipe as diferenças de opinião, de visão profissional, de escolaridade, de cultura de segurança do paciente, de comportamento, de hierarquização profissional e de responsabilização com o paciente, podendo gerar eventos adversos durante a assistência (MARCHON; JUNIOR; PAVÃO, 2015; PEÑA et al., 2015). Há ainda apontamentos sobre queixas de pacientes terem sido prejudicados durante o cuidado assistencial. Possivelmente isso seria evitado com uma comunicação efetiva, quando os profissionais ouvem a opinião dos pacientes (MADDEN et al., 2019).

Outro fator importante para a SP é o fato de algumas categorias profissionais passarem mais tempo ao lado do paciente durante sua jornada de trabaIho. Isso faz com que percebam mais negativamente a comunicação e fatores relacionados ao erro entre pacientes e outros profissionais, pois conseguem observar seu relacionamento (BODUR; FILIZ, 2009). Estudo com a equipe multiprofissional, no entanto, demonstra que foram encontradas médias positivas para comunicação e aprendizagem sobre o erro (VERBAKEL et al., 2014)

Outra pesquisa reforça que a comunicação foi evidenciada negativamente tanto pela equipe de saúde quanto pela administrativa. Isso revela atenção, pois a boa comunicação entre a equipe leva à aprendizagem organizacional (GHOBASHI et al., 2014). Em contraponto, outro autor evidencia que a comunicação foi avaliada mais positivamente pela equipe de enfermagem do que a categoria de Agentes Comuni- tários de Saúde (ACS). Este achado pode ocorrer pelo fato de que o ACS realiza suas atividades laborais majoritariamente na comunidade, sendo menor seu contato com a equipe e o compartilhamento do mesmo ambiente de trabalho, pois faz-se presente no local de saúde quando necessita trocar informações com os colegas ou enfermeiro supervisor, o que explica perceber de forma diferente este achado (PAESE; DAL SASSO, 2013).

Quanto à Condição de Trabalho, evidencia-se que o tempo maior de trabalho no serviço de saúde é um dos fatores que implica negativamente a SP na APS. Isso está relacionado a um aumento na percepção de erros ao longo do tempo e a uma crescente conscientização da equipe sobre problemas de segurança. Ainda pode estar relacionado à maior disposição para admitir problemas de segurança, uma vez que a equipe ganha mais experiência trabalhando vários anos em uma unidade (PEÑA et al., 2015; BODUR; FILIZ, 2009).

Outra pesquisa, no entanto, destaca que os profissionais que trabalham há mais de 10 anos no serviço de saúde podem favorecer o planejamento, a organização, o conhecimento da área adscrita, os usuários cadastrados, o fortalecimento do vínculo, colaborando para uma melhor cultura de segurança (SOUZA et al., 2019). Os profissionais que possuem idades igual ou superior a 50 anos também evidenciam escores positivos nas dimensões condições de trabalho e satisfação no trabalho e isso pode ser atribuído a maiores experiências laborais, o que aumenta a afiliação dos indivíduos ao seu trabalho, bem como aumenta sua tolerância a condições de trabalho variáveis (SHAFEl; ZAYED, 2019). Outro estudo, denota não haver relação entre os anos de trabalho e a pontuação de CSP (TABRIZCHI; SEDAGHAT, 2012).

A sobrecarga de trabalho também é um fator relacionado à CSP na APS, quando os profissionais sentem-se pressionados para atender o paciente, muitas vezes devido à alta demanda do serviço (MACEDO et al., 2019). Profissionais de saúde que atendem menos de mil pacientes apresentaram maior pontuação do índice sintético de Segurança do Paciente, comparados àqueles profissionais com responsabilidades sobre uma demanda de mil a mil e quinhentos pacientes, destacando que a menor pontuação foi para os profissionais de atendem acima de mil e quinhentos pacientes (PEÑA et al., 2015). A sobrecarga de trabalho também foi evidenciada como dimensão mais baixa em outros estudos, demonstrando que exige ações destinadas para articular promoção de saúde e adaptar o planejamento de recursos humanos para 
atender à demanda de usuários (HICKNER et al., 2015; ROMERO; GONZÃLEZ; CALVO, 2017; ASTUDILLO et al., 2015).

Ainda evidencia-se sobrecarga de trabalho quando o número de funcionários das unidades de saúde é padronizado. A migração das pessoas para os subúrbios aumenta a população correspondente às unidades saúde, exigindo mais do pessoal assistencial. Somada a este fator, a sobrecarga aumenta quando nenhuma nova unidade de saúde é construída ao longo dos anos (LAWATI et al., 2019).

Enfermeiros evidenciam de forma negativa o clima de segurança quando há inadequada distribuição de pessoal, fazendo com que realizem mais de um serviço por turno, levando a uma maior carga de trabalho (SHAFEI; ZAYED, 2019). Profissionais farmacêuticos identificam problemas de rotina no trabalho diário, como falta de medicamentos essenciais fornecidos à farmácia, levando a longos debates com os clientes, bem como a desigualdade na carga de trabaIho ao longo do mês (SHAFEI; ZAYED, 2019).

As condições de trabalho também relacionam-se com o clima e a satisfação no trabalho, pois esta última foi evidenciada negativamente por médicos, comparados com enfermeiros. Isto pode estar relacionado ao fato de que os médicos atuam em mais de um local de trabalho, e enfermeiros normalmente são empregados em apenas um local, fazendo com que haja um maior grau de apego ao seu ambiente de trabalho e entre a equipe, resultando em uma maior satisfação laboral (BONDEVIK et al., 2014) Isso pode estar atribuído às altas taxas de rotatividade e de absenteísmo entre os médicos (SHAFEl; ZAYED, 2019). Em contraponto, outra análise destaca que enfermeiros apresentaram maior percentual significativo para cultura negativa no domínio Satisfação no Trabalho (ERICSSON et al., 2019).

Presume-se que nos serviços que identificam uma CSP baixa ou desigual entre os servidores, faz-se necessário redefinir os valores e qualificar a motivação profissional, realizar discussões sobre o processo de trabalho, incentivar práticas do cuidado seguro, instalar protocolos assistenciais de gestão de riscos e prevenção de incidentes (RAIMONDI et al., 2019).

As circunstâncias relacionadas a condições de trabalho foi uma das atitudes de segurança destacadas entre a percepção da equipe de enfermagem e ACS, observando-se que a média para ACS foi menor. Este fato justifica-se porque o ACS não compartilha uma longa jornada de trabalho com a equipe que está alocada em uma unidade de saúde, posto que a maioria das suas atividades é direcionada para a comuni- dade, podendo representar a visão dos usuários em relação ao serviço de saúde (RAIMONDI et al., 2019). A equipe de enfermagem, no entanto, sente intimamente os problemas relacionados com matéria-prima e recursos humanos na unidade de saúde, com os profissionais de enfermagem sendo os que compensam a falta de recursos humanos nos diferentes setores de saúde, colaborando para a sobrecarga de trabalho, comprometendo a qualidade da assistência (PAESE; DAL SASSO, 2013)

$O$ fator liderança demonstra que quando os líderes da APS evidenciam melhor a SP, há uma cultura de segurança positiva no local e estes trabalham para garantir que os cuidados sejam prestados de forma segura, pois utilizam diferentes ferramentas para identificar lacunas e criar sistemas eficazes (PEÑA et al., 2015; GORMAN; OMALLEY; FAGNAN, 2012). Também está relacionado ao treinamento gerencial, à experiência profissional (TABRIZCHI; SEDAGHAT, 2012) ou ao fato de os gestores acreditarem que sua CSP é mais forte do que realmente é (HICKNER et al., 2015)

Pesquisa indica que líderes apresentam maiores percentuais de atitude positiva para satisfação no trabalho, clima da equipe, percepção da gerência, condições de trabalho e clima de segurança. Profissionais de saúde que trabalham em posições de liderança deveriam ser mais positivos em relação às questões de segurança do paciente na prática pela qual são responsáveis, em comparação com os demais funcionários (SHAFEl; ZAYED, 2019).

Estudo mostra que os gestores que aceitam as sugestões do pessoal para melhorar a SP são vistos de maneira positiva pela equipe (ASTUDILLO et al., 2015), bem como aqueles que participam na supervisão das atividades laborais, no contato e valorização do trabaIho da equipe, pois isso favorece o vínculo de confiança e a união da equipe (SOUZA et al., 2019).

Há gestores da APS em países menos desenvolvidos, entretanto, que não estão abertos a ideias inovadoras e os funcionários não são encorajados a manifestar pontos de vista alternativos ou a expressar discordância. Este fato ocorre porque há um cultura de que o desacordo e a crítica contra supervisores ou membros da equipe são frequentemente interpretados como culpa ou ação contra eles, o que pode levar à perda de relacionamento pessoal ou de carreira, de modo que a maioria dos funcionários tende a evitá-los (WEBAIR et al., 2015).

Investigação revela que os os profissionais de saúde mostram insatisfação com os seus gestores (MACEDO et al., 2019) e que estes necessitam melho- 
rar e favorecer a comunicação entre o grupo, alocar corretamente os recursos e valorizar os profissional de sua equipe (RAIMONDI; BERNAL; MATSUDA, 2019).

Outra pesquisa mostra diferentes percepções sobre o gerenciamento, quando comparadas à equipe de ACS e enfermeiros. Este fato pode ocorrer pela relação entre os profissionais, porque na maioria das situações é o enfermeiro que exerce cargo de supervisor em relação ao ACS, e muitas vezes esta relação ocorre de forma hierarquizada (PAESE; DAL SASSO, 2013; RAIMONDI et al., 2019).

\section{CONSIDERAÇÕES FINAIS}

A análise dos estudos primários que compuseram o corpus da revisão em tela permitiu concluir que os fatores educação permanente, comunicação, condições de trabalho e liderança interferem na CSP na APS, pois intervêm diretamente nas ações de cuidados diárias. Alguns destes fatores mostram-se como pontos positivos, reforçando as ações que fortalecem a CSP na APS. Outros fatores mostram-se negativos, indicando a necessidades de busca de estratégias para superar os desafios que fragilizam a CSP na APS.

Observou-se o número discreto e crescente nos últimos anos de produções tendo como objeto de estudo a SP na APS, o que revela a necessidade do desenvolvimento de pesquisas que contemplem essa temática com vistas à contribuição da produção do conhecimento, implicando também, a tomada de decisão clínica para minimizar a ocorrência de EA nos ambientes de saúde e fortalecer a integralidade da atenção à saúde respaldada em evidências com maior grau de recomendação.

\section{REFERÊNCIAS}

ASTUDILLO, M. N. M. et al. Percepción de trabajadores sobre la cultura de seguridad del paciente en una empresa de salud. Revista Cultura del Cuidado, 2015. Disponível em: http://repositorio.unilibrepereira.edu.co:8080/Viewer/index.jsp?file=123456789/475/Art\%20No\%204\%20ESEseguridad.pdf.

BODUR, S.; FILIZ E. A survey on patient safety culture in primary healthcare services in Turkey. International Journal for Quality in Health Care, 2009. DOI: 10.1093/intqhc/mzp035.

BONDEVIK, G. T. et al. Patient safety culture in Norwegian primary care: A study in out-of-hours casualty clinics and GP practices. Scandinavian Journal of Primary Health Care, 32, p. 132-138, 2014. DOI: 10.3109/02813432.2014.962791.
BRASIL. Ministério da Saúde. Portaria no 2.436, de 21 de setembro de 2017. Dispõe sobre a Política Nacional de Atenção Básica [internet]. Brasília, 2017. Disponível em: http://bvsms.saude.gov.br/bvs/saudelegis/gm/2017/ prt2436_22_09_2017.html. Acesso em: 10 out. 2018.

CASALENGUA, M. L. T. et al. Validación de un cuestionario para evaluar la cultura de seguridad del paciente de los profesionales de atención primaria en España. Aten Primaria, 45(1), p. 21-37, 2013. DOI: http://dx.doi.org/10.1016/j. aprim.2012.07.003

ERICSSON, C. et al. Can patients contribute to safer care in meetings with healthcare professionals? A cross-sectional survey of patient perceptions and beliefs. BMJ Qual Saf, 28, p. 657-666, 2019. DOI:10.1136/bmjqs-2018-008524

FINEOUT-OVERHOLT, E.; STILLWELL, S. B. Asking compelling, clinical questions. In: MELNYK, B. M.; FINEOUT-OVERHOLT, E. (ed.). Evidence-based practice in nursing \& healthcare. A guide to best practice. Philadelphia: Wolters Kluwer; Lippincott Williams \& Wilkins, 2011.

GEHRING, K. et al. Safety climate and its association with office type and team involvement in primary care. Int J Qual Health Care, 25(4), p. 394-402, 2013. DOI: 10.1093/intqhc/ mzt036.

GHOBASHI, M. M. et al. Assessment of Patient Safety Culture in Primary Health Care Settings in Kuwait. Epidemiology Biostatistics and Public Health, 2014. Disponível em: https://ebph.it/article/view/9101.

GONZÁLEZ-FORMOSO, C. et al. Effectiveness of an educational intervention to improve the safety culture in primary care: a randomized trial. I. BMC Family Practice, 20, p. 15, 2019. Disponível em: https://doi.org/10.1186/s12875-0180901-8.

GORMAN, P. N.; O'MALLEY, J. P.; FAGNAN, L. J. The Relationship of Self-Report of Quality to Practice Size and Health Information Technology. JABFM, Sep./Oc. 2012. DOI: 10.3122/jabfm.2012.05.120063.

HICKNER, J. et al. Differing perceptions of safety culture across job roles in the ambulatory setting: analysis of the AHRQ Medical Office Survey on Patient Safety Culture. BMJ Qual Saf, 0, p. 1-7, 2015. DOI: 10.1136/bmjqs-2014-003914.

HOFFMANN, B. et al. Effects of a team-based assessment and intervention on patient safety culture in general practice: an open randomised controlled trial. BMJ Qual Saf, 23, p. 35-46, 2014. DOI: 10.1136/bmjqs-2013-001899.

LAWATI, M. H. A. et al. Assessment of patient safety culture in primary health care in Muscat, Oman: a questionnaire -based survey. BMC Family Practice, 20, p. 50, 2019. Disponível em: https://doi.org/10.1186/s12875-019-0937-4

MACEDO, S. M. K. et al. Cultura de segurança do paciente: avaliação dos enfermeiros na atenção primária à saúde. Enfermería Global, n. 56, out. 2019. Disponível em: http://dx. doi.org/10.6018/eglobal.18.4.352261.

MADDEN, C. et al. Safety in primary care (SAP-C): a randomised, controlled feasibility study in two different healthcare systems. BMC Family Practice, 20, p. 22, 2019. https:// doi.org/10.1186/s12875-019-0909-8. 
MAKEHAM, M. et al. Methods and measures used in primary care patient safety research. Geneva: World Health Organization. 2008. Disponível em: https://www.who.int/ patientsafety/research/methods_measures/makeham_dovey_full.pdf?ua=1.

MARCHON, S. G.; JUNIOR, W. V. M.; PAVÃO, A. L. B. Characteristics of adverse events in primary health care in Brazil. Cad Saúde Pública, 31(11), p. 2.313-2.330, 2015. DOI: http://dx.doi.org/10.1590/0102-311X00194214.

MENDES, K. D. S.; SILVEIRA, R. C. C. P.; GALVÃO, C. M. Revisão integrativa: método de pesquisa para incorporação de evidências na saúde e na enfermagem. Texto \& Contexto Enferm., 17 (4), p. 758-64, 2008. Disponível em: http:// www.scielo.br/pdf/tce/v17n4/18.pdf.

NATIONAL PATIENT SAFETY FOUNDATION. Free from Harm: Accelerating Patient Safety Improvement Fifteen Years after To Err Is Human [Internet]. 2015. Disponível em: http:// www.npsf.org/?page=freefromharm. Acesso em: 18 fev. 2018)

ORNELAS, M. D.; PAIS, D.; SOUSA, P. Patient Safety Culture in Portuguese Primary Health care. Qual Prim Care [Internet], 24(5), p. 214-18, 2016. Disponível em: http://primarycare.imedpub.com/patient-safety-culture-in-portuguese-primary-healthcare.pdf. Acesso em: 18 set. 2018.

PAESE, F.; DAL SASSO, G. T. M. Patient safety culture in primary health care. Texto Contexto Enferm., 22(2), p. 302-10, 2013. DOI: http://dx.doi.org/10.1590/S010407072013000200005.

PEÑA, M. P. A. et al. Are Spanish primary care professionals aware of patient safety? European Journal of Public Health, v. 25 , n. 5, p. 781-787, 17 nov. 2015. DOI: 10.1093/eurpub/ ckv066.

RAIMONDI, D. C. et al. Cultura de segurança do paciente na atenção primária à saúde: análise por categorias profissionais. Rev. Gaúcha Enferm., 40(esp), p. e20180133, 2019. DOI: https://doi.org/10.1590/1983-1447.2019.20180133

RAIMONDI, D. C.; BERNAL, S. C. Z.; MATSUDA, L. M. Cultura de segurança do paciente na ótica de trabalhadores e equipes da atenção primária. Rev. Saúde Pública, 53, p. 42, 2019. DOI: https://doi.org/10.11606/ S1518-8787.2019053000788.

REE, E.; SIRI, W. Employees' perceptions of patient safety culture in Norwegian nursing homes and home care services. BMC Health Services Research, 19:607, 2019. Disponível em: https://doi.org/10.1186/s12913-019-4456-8.

ROMERO, M. P.; GONZÁLEZ, R. B.; CALVO, M. S. R. La cultura de seguridad del paciente en los médicos internos residentes de Medicina Familiar y Comunitaria de Galicia. Aten. Primária, 49(6), p. 343-50, 2017. DOI: https://doi.org/10.1016/j.aprim.2016.09.009.

SHAFEI, A. M. H. E.; ZAYED, M. A. Patient safety attitude in primary health care settings in Giza, Egypt: Cross-sectional study. Int J Health Plann Mgmt., 34, P. 851-861, 2019. DOI: 10.1002/hpm. 2743.

SORRA, J. et al. Agency for Health care Research and Quality. Medical Office Survey on Patient Safety Culture: User's Guide [Internet]. 2016. Disponível em: https://www.ahrq. gov/sites/default/files/wysiwyg/professionals/quality-patient-safety/patientsafetyculture/medical-office/userguide/ mosurveyguide.pdf. Acesso em: 12 set. 2018.

SOUZA, M. M. et al. Patient safety culture in the Primary Health Care. Rev. Bras. Enferm. [Internet], 72(1), p. 27-34, 2019. DOI: http://dx.doi.org/10.1590/0034-7167-20170647.

TABRIZCHI, N.; SEDAGHAT, M. The First Study of Patient Safety Culture in Iranian Primary Health Centers. Acta Medica Iranica, v. 50, n. 7, 2012. Disponível em: https://www.ncbi. nlm.nih.gov/pubmed/22930384.

TIMM, M.; RODRIGUES, M. C. S. Cross-cultural adaptation of safety culture tool for Primary Health Care. Acta Paul Enferm., 29(1), p. 26-37, 2016. DOI: http://dx.doi. org/10.1590/1982-0194201600005.

VERBAKEL, N. J. et al. Effects of patient safety culture interventions on incident reporting in general practice: a cluster randomised trial. British Journal of General Practice, May 2015b. DOI: 10.3399/bjgp15X684853.

VERBAKEL, N. J. et al. Exploring patient safety culture in primary care. International Journal for Quality in Health Care, 2014. Disponível em: https://doi.org/10.1093/intqhc/ mzu074.

VERBAKEL, N. J. et al. Improving patient safety culture in general practice: an interview study. British Journal of General Practice, Dec. 2015a. DOI: 10.3399/bjgp15X687865.

WEBAIR, H. H. et al. Assessment of patient safety culture in primary care setting, Al-Mukala, Yemen. BMC Family Practice, 16(136), p. 1-9, 2015. DOI: 10.1186/s12875-015-0355-1. 